\title{
Desafíos de la comunicación popular y comunitaria en Ecuador. La experiencia de ALER
}

Challenges of popular and community communication in Ecuador. The experience of ALER

Desafios da comunicação popular e de comunicação no Equador. A experiência do ALER

\section{Nicole Stefania VALLEJO MARURI}

Universidad Politécnica Salesiana/nicky-vallejo@hotmail.com

\section{Tania VILLALVA SALGUERO}

Universidad Politécnica Salesiana/villalva@ups.edu.ec

Chasqui. Revista Latinoamericana de Comunicación

N. ${ }^{\circ}$ 146, abril-julio 2021 (Sección Monográfico, pp. 43.58)

ISSN 1390-1079 / e-ISSN 1390-924X

Ecuador: CIESPAL

Recibido: 14-09-202O/Aprobado: 02-12-2O2O 


\title{
Resumen
}

En este estudio se analiza las práctica comunicativas radiofónicas de ALER, su construcción histórica, el acercamiento y acompañamiento a comunidades y sectores subalternizados del Ecuador, América Latina y el Caribe; desde un enfoque cualitativo y un muestreo no probabilístico, se realizó entrevistas semiestructuradas a los directivos locales e internacionales, se construyó una matriz para revisar el discurso presente en las narrativas sonoras de los programas insignias y mirar cuál es el aporte social desde los contenidos. ALER ha sido un ícono en la conceptualización de la comunicación y la radio popular, su trabajo permitió el desarrollo organizativo, y posterior reconocimiento político de líderes y comunidades indígenas, amazónicos y afrodescendientes; sin embargo, lo popular y comunitario está subestimado, pues el mayor reto es competir con contenidos que se viralizan con facilidad sin mayor propuesta de contenido.

Palabras clave: comunicación; comunicación popular; comunicación comunitaria; comunidades; radio popular; radio comunitaria

\begin{abstract}
This study analyzes the radio communication practices of ALER, its historical construction, the approach and accompaniment to communities and subalternized sectors of Ecuador, Latin America and the Caribbean; From a qualitative approach and a non-probabilistic sampling, semi-structured interviews were conducted with local and international managers, a matrix was built to review the discourse present in the sound narratives of the flagship programs and see what the social contribution is from the contents. ALER has been an icon in the conceptualization of communication and popular radio, its work allowed the organizational development, and subsequent political recognition of indigenous, Amazonian and Afro-descendant leaders and communities. However, what is popular and community is underestimated, since the biggest challenge is competing with content that goes viral easily without a major content proposal.
\end{abstract}

Key words: communication; popular communication; community communication; communities; popular radio; community radio

\section{Resumo}

Este estudo analisa as práticas de radiocomunicação do ALER, sua construção histórica, a aproximação e acompanhamento de comunidades e setores subalternizados do Equador, América Latina e Caribe; A partir de uma 
abordagem qualitativa e de uma amostragem não probabilística, foram realizadas entrevistas semiestruturadas com gestores locais e internacionais, foi construída uma matriz para revisar os discursos presentes nas narrativas sonoras dos programas carro-chefe e verificar qual a contribuição social dos conteúdos. ALER tem sido um ícone na conceituação de comunicação e rádio popular, seu trabalho permitiu o desenvolvimento organizacional e consequente reconhecimento político de lideranças e comunidades indígenas, amazônicas e afrodescendentes; No entanto, o que é popular e comunitário é subestimado, pois o maior desafio é competir com um conteúdo que se torna viral facilmente sem uma grande proposta de conteúdo.

Palavras-chave: comunicação; comunicação popular; comunicação comunitária; comunidades; rádio popular; rádio comunitária

\section{Introducción}

La Asociación Latinoamericana de Educación Radiofónica (ALER) se consolida en el año 1972; su propósito inicial enmarcaba la comunicación educativa y el aporte a los procesos organizativos en la reivindicación de los derechos de los pueblos y nacionalidades indígenas, afrodescendientes y criollas de América Latina. A partir de 1989, posterior a la VII Asamblea General de ALER, desarrollada en la ciudad de Quito-Ecuador, se pone en marcha el Proyecto ALER 500 Años, mismo que impulsó la producción radiofónica y que mantiene el vínculo y trabajo con los pueblos originarios.

En estos 48 años, ALER se ha desarrollado desde tres etapas: en una primera instancia se la reconoció como una red de radios evangelizadoras, orientadas desde la teoría de la liberación de Paulo Freire, desarrollada en el año 1972. En sus inicios, fueron dieciocho radios de la iglesia católica que se sumaban a este trabajo, con una específica intención, alfabetizar al sector rural desde una metodología pedagógica entendida como "a distancia".

Este proceso fue inspirado desde la vertiente católica en 1947 en Colombia, en el pueblo Sutatenza del departamento de Boyacá; el Padre Joaquín Salcedo experimentaba y difundía equipos radioaficionados, para así lograr los primeros programas radiales direccionados a los campesinos de la región. La pionera de las experiencias de la Iglesia Católica latinoamericana fue Acción Cultural Popular (ACPO) más conocida como Radio Sutatenza; experiencia que permitió conceptualizar la radio educativa y posterior las escuelas radiofónicas.

Las características básicas del modelo Sutatenza se pueden expresar en la consigna "alfabetizar y evangelizar a todo dar". Con la alfabetización y la educación de adultos se pensaba resolver el problema de la pobreza. Los campesinos se desarrollarían si aprendían a leer y escribir. (Sánchez, 1989, p. 58) 
Sin embargo, la educación formal que se realizaba por radio sufrió un descenso, pues los servicios estatales de educación básica gratuita se extendieron a los lugares apartados, y denotaron que no se solucionan los problemas de pobreza y marginación de los sectores populares con el aprendizaje de la escritura y lectura. Entonces, aparecen nuevos proyectos radiales en el ámbito de comunicación y educación.

En un segundo momento, trasciende la radio educativa y se instaura la radio popular y comunitaria, esta sin duda es la etapa más importante para ALER, pues se evidencia la ideología de trabajo y se logra aterrizar en prácticas comunicativas que aportaban al fortalecimiento y reconocimiento de la identidad étnica y de sociedades interculturales. Por lo tanto, las producciones apuntaban al rescate cultural, pero sobre todo a la posibilidad de trascender continentalmente; dicho trabajo significó un aporte importante a los procesos organizativos de las comunidades indígenas y de las diferentes nacionalidades, ya que era al interior de las comunas que se construían programas radiales.

El surgimiento de este proceso comunicativo revolucionario recurre a una visión más amplia: la sindicalista, en Bolivia, en el año 1952. "A cuatro mil metros de altura, en pleno altiplano boliviano, en el llamado campamento Siglo $\mathrm{XX}$, se inaugura la primera emisora de la clase trabajadora latinoamericana, 'La Voz del Minero"' (Sánchez, 1989, p. 59). Aquellos integrantes de grupos mineros, fabriles y campesinos, que mantienen un tipo de asociación, buscaban ampliar su dominio, llegar a más personas, hacerse oír y fortalecer sus organizaciones. Los obreros mantenían la radio con el dinero de su trabajo, decidían qué programación se transmitía. "Concientizar y luchar para el mundo, transformarlo podría ser la consigna que resuma los objetivos originales de la radio sindical" (Sánchez, 1989, p. 59).

Finalmente, ALER se ubica en una etapa de incidencia, pues participa en procesos legislativos políticos en torno a la consolidación de la Ley Orgánica de Comunicación del Ecuador, puesta en vigencia en el año 2013. Buscaba aportar a la democratización de la palabra, la reivindicación del derecho a la comunicación, la información y la libre expresión de los pueblos, comunidades rurales, sectores periféricos y marginados; de esta manera, se podía garantizar el acceso a medios desde un concepto pluralista.

Este camino histórico que la comunicación popular y comunitaria recorre, permite entender de qué manera Ecuador se convierte en uno de los países referentes sobre la radio como alfabetizadora, evangelizadora y popular que adopta la iniciativa. "En América Latina hay cerca de 10 mil radios comunitarias. Perú es el país que más tiene, seguido de Ecuador, Bolivia y Brasil. Si se cuentan también las que emiten sin licencia, el número total de radios comunitarias es mucho mayor" (Unesco, 2020). "En Ecuador existen 55 radios comunitarias (hasta junio de 2017), pero la realidad es que hay 25 emisoras con distintos alcances" (Beltrán, 2018, p. 67). 
Las prácticas de ALER, a través del discurso radiofónico, se enmarcan en la teoría de la acción colectiva, la misma "delimita que el capital social formado por redes de reciprocidad, cooperación voluntaria y compromiso contribuye a la formación de la comunidad" (Vargas, 2003, p. 529); en este sentido la práctica colectiva del quehacer radial representa códigos y símbolos de un discurso intercultural y de derechos, lo qué históricamente ha dado sentido al trabajo con las comunidades.

Este trabajo en comunidad y construcción colectiva se ha vinculado a acciones de resistencia, protesta, cambio social, que han sido promovidas por los sectores populares y comunitarios de la sociedad ecuatoriana y de América Latina. "Es decir, que lo educativo, lo popular y lo comunitario, se define por los actores que protagonizan la comunicación" (Amati, Isella, \& Lois, 2014, p. 9).

Es así como la comunicación popular surge en el Ecuador como parte de una ideología que promueve el derecho a la comunicación de las organizaciones indígenas y campesinas pertenecientes a la zona sierra centro del país; su propósito inicial fue encaminar a promover el derecho a la comunicación y a establecer espacios de participación dentro de la comunidad, para de esta forma empoderar el concepto de comunidad en la misma.

Gracias a los procesos desarrollados por ALER se logró establecer la noción de radio popular; como plantea Hernán Gutiérrez (1997), la radio popular permitió abrir nuevos debates desde los sectores populares hacia la sociedad en general, lo que a su vez marcó una agenda distinta de las cotidianidades, se fueron trazando temáticas diversas que mostraban el entendimiento de una comunicación pionera en la búsqueda de consensos.

Se evidencia las conexiones sociales y se visibiliza el trabajo de la comunicación en el proceso de los movimientos sociales, quienes reflejan "un carácter simbólico capaz de cohesionar y articular e incluso generar nuevos actores colectivos a través de su discurso para legitimar a través de él las demandas sociales, económicas y políticas de la época, para actuar incluso tras la figura de movimiento" (Pico, 2009, p. 34).

Por lo tanto, el trabajo de ALER ha sido significativo, ya que posibilitó el surgimiento de los sectores subalternizados y el empoderamiento de sus derechos a través de la comunicación; este proceso se instaura como una red de redes a escala continental, que desde la comunicación para el desarrollo ha buscado generar cambios tanto en el ámbito social, político, cultural y hasta económico en las regiones en las cuales trabaja.

En este sentido, la presente investigación espera responder la siguiente pregunta: ¿̇de qué manera las prácticas comunicativas radiofónicas que desarrolla ALER, mantiene vigencia y corresponsabilidad con el desarrollo de los sectores populares, y cuáles son los desafíos de la radio popular y comunitaria actualmente en Ecuador? Para ello se estructura dos objetivos: 1. Establecer la ideología y el discurso que fundamenta y orienta el trabajo de ALER desde 
la perspectiva de sus directivos. 2. Analizar las producciones radiofónicas de alcance continental y el aporte social a partir del contenido.

Para cumplir con este propósito, se organizó la información del artículo de la siguiente manera: se realizó un recorrido teórico-conceptual que evidencia la construcción de lo popular desde la acción colectiva, las practicas radiofónicas y la vinculación con las comunidades y sectores subalternizados; posterior a ello, se trazó un diseño metodológico cualitativo desde un muestreo no probabilístico que se consolidó a través de entrevistas semi estructuradas y una matriz para el análisis discursivo de los programas radiales, de ahí se establecieron la discusión, los resultados y finalmente las conclusiones.

\section{Discusión teórica}

\subsection{La concepción de lo popular}

Lo popular, según la sociedad es lo que pertenece y crea el pueblo, es lo propio de las clases sociales bajas. Sin embargo, esto va más allá, para los sectores populares es parte de su organización, cooperación, aportación, levantamiento. Lo popular ha generado en estos sectores la libre expresión.

"El término popular suele referir a un posicionamiento en favor de los intereses de los sectores populares y el vínculo más o menos directo con sus organizaciones representativas" (Kaplún, 2007, p. 312). Mientras que para Busso (2020) lo popular se puede considerar con un significado político; son los aislados, los obreros y los marginados. Es un enfrentamiento entre las personas de poder y el pueblo.

Entender lo popular es entender al pueblo, de ahí que para Kaplún (2007) la comunicación popular es una extensión de lo popular. Entonces ¿qué es la comunicación popular si lo popular es del pueblo? Jesús Martín-Barbero (citado en Motta, 1983) habla de comunicación en dos sentidos; por una parte, está la clase popular que hace referencia a la situación de clase, y desde otra perspectiva, se encuentran las dominadas o conocidas como subalternas.

Alaiza (2002), por su parte, reconoce a la comunicación popular como una práctica de intercambio cultural y simbólico entre los actores sociales; este proceso interlocutor fundamenta las características culturales desde el reconocimiento de las diferencias, por lo tanto, esta comunicación trabaja desde ámbitos interculturales.

\subsection{Las mediaciones y actores sociales}

El trabajo radiofónico de ALER, a través de las narrativas sonoras y su vinculación con las comunidades marginadas, representó en el Ecuador el simbolismo de la radio popular, lo que significó entender a la radio como una unidad, esta figura de sujeto se vuelve en el constructor o mediador de los proyectos globales que 
ALER lideraba, y que por consiguiente, pretendía construir sociedades más democráticas y pluralistas.

El propio modo de nombrarse de esas radios en el cual los sectores populares ocupan un lugar central como sujeto, fuente y destino de su acción. Reconocerse populares implica un posicionamiento global frente a un sistema económico-social en el cual dichos sectores - sin importar de qué grupos se trate o dónde estén ubicados geográficamente - son marginados o excluidos también globalmente del poder. Y no solo del poder comunicar. (Mata, 1993, p. 59)

Las radios populares y comunitarias no aparecieron para mejorar la situación de comunicación en un territorio, surgen de la necesidad de democratización de la palabra y la información, es una respuesta contra hegemónica, que visibiliza realidades diferentes, muestra necesidades ocultas, presenta intereses y logros individuales de las comunidades y sectores marginados. En este sentido, ALER se consolida como el centro de producciones dinamizado por todas las radios filiales en América Latina y el Caribe.

Las 18 organizaciones fundantes de ALER recurren a esta forma de participación en la política pública mediante la conformación de una asociación, a través de la cual se buscaba fortalecer el vínculo entre la comunicación radiofónica, la educación y alfabetización de los pueblos latinoamericanos; es decir, que la acción colectiva de esta asociación, surgió como dice Tarrow, como una forma de respuesta al momento histórico que les demandaba: una acción a favor de la alfabetización y la promoción de la educación de las comunidades marginadas, pobres y analfabetas donde cada una de las asociadas tenía su audiencia y su radio de acción. (Pico, 2009, p. 29)

\subsection{Comunicación popular y comunicación comunitaria}

Si la comunicación popular se relaciona directamente con las clases populares, es decir, los sectores subalternos, la comunicación comunitaria se consolida desde los principios y valores de la convivencia comunitaria propia de estos sectores.

Se debe de tomar en cuenta que "son los actores populares y comunitarios, como protagonistas del proceso comunicativo, los únicos que pueden protagonizar la comunicación popular y comunitaria. Son ellos, con sus cargas culturales, políticas, ideológicas" (Amati, Isella, \& Lois, 2014, p. 10).

Los medios de comunicación comunitarios representan una oportunidad real para democratizar la comunicación, pues su trabajo responde a necesidades informativas reales de los diversos conglomerados sociales. Aquí el ejercicio periodístico no da cuentas a poderes económicos sino a los integrantes de una comunidad que intenta debatir y consensuar sobre problemáticas políticos y sociales que influyen en su vida cotidiana. (Sánchez, 2018, p. 136) 
Según el Documento de la Coordinadora en Defensa de la Comunicación Comunitaria, Alternativa y Popular (2011) las concepciones tanto de los medios comunitarios, alternativos y populares buscan edificar los diferentes lazos de la comunicación, aseguran la diversidad de voces, ocupan el compromiso en la edificación de las identidades culturales, manifiestan diferentes realidades que son ajenas a lo que ocurre en la corporaciones mediáticas, buscan una comunicación solidaria, participativa y plural, que se realiza para resguardar los interés de los sectores populares.

Los medios de comunicación en todas sus formas son vitales para la sociedad, para la generación del debate, y para la concreción de acuerdos sociales, por ello es importante repensar en su función social y avanzar hacia la diversificación de esos espacios. Los medios alternativos y comunitarios son necesarios para avanzar con la lógica de descentralizar la comunicación y apartarla de los poderes económicos. (Sánchez, 2018, p, 136)

Además, la consolidación de la comunicación popular y comunitaria es resultado de un proceso hegemónico globalizado, donde los grandes medios privados que pertenecen a los grupos de poder económico y político, a escala país, y de manera mundial, rigen la agenda mediática de la sociedad; en este sentido, surgen como la postura contra hegemónica y anti-sistémica que garantiza la pluralidad de voces.

\section{Diseño metodológico}

Dado que esta investigación espera estudiar las prácticas comunicativas radiofónicas de ALER y su incidencia en el desarrollo de los sectores populares, se consideró trabajar desde el paradigma interpretativo de la comunicación, es decir, entender la construcción de una realidad desde la perspectiva del grupo social que se ve influenciado por este tipo de comunicación y radio. "No existe una sola verdad, sino que surge como una configuración de los diversos significados que las personas le dan a las situaciones en las cuales se encuentra" (Rodríguez, 2011, p. 9).

Además, se trabajó desde una perspectiva descriptiva, que permitió analizar los fenómenos sociales desde la comunicación y la radio popular o comunitaria, determinó el recorrido histórico y su trascendencia en América Latina y el Caribe, en este caso particular ALER y sus 48 años en el Ecuador. Desde una muestra no probabilística y un enfoque cualitativo, se evidenció el alcance del estudio, ya que "la metodología cualitativa es como la investigación que produce datos descriptivos: las propias palabras de las personas, habladas o escritas, y la conducta observable" (Quecedo Lecanda \& Castaño Garrido, 2002, p. 7).

Desde esta estructura se plantearon dos técnicas de recolección de información: la primera fue la entrevista semi estructurada, para ello se realizó un acercamiento a directivos nacionales e internacionales y personajes 
involucrados en procesos radiales populares; los entrevistados fueron: Roció Huamancondor, parte del equipo núcleo de innovación institucional en ALER; Leonel Herrera, director ejecutivo de ARPA (Red de Radios Populares de El Salvador.) y presidente de la junta directiva de ALER; Hugo Ramírez, Coordinador General de ALER; finalmente; Olmedo Carrasquilla, periodista de Radio Temblor, radio popular en Panamá.

A través de este proceso interlocutor se buscó contextualizar el papel de ALER y sus procesos comunicativos desde lo popular y comunitario en Ecuador, América Latina y El Caribe, la descripción de los programas y producciones radiofónicas, el vínculo con las comunidades indígenas, campesinas, afrodescendientes y sectores marginales, finalmente, conocer las ideologías frente a los retos y proyecciones de la radio popular y comunitaria en el país.

Eliseo Verón (1993) se refería a lo ideológico desde el análisis discursivo, pues entender la postura de las personas y que esta pueda ser explicada desde los espacios de enunciación, permite darle sentido a las posibles predicciones de una temática específica; en este mismo sentido, van Dijk especifica que "la elección de palabras específicas puede señalar el grado de formalidad, la relación entre los participantes en el habla, la inserción institucional o grupal del discurso, y en especial las actitudes y, en consecuencia, las ideologías del hablante" (Van Dijk, 1980, p.122).

La segunda técnica utilizada fue la matriz de análisis del discurso de los programas radiofónicos insignias de ALER, cuya elección se enmarco desde la postura de los entrevistados, pues ellos fueron quienes coincidieron en los programas representativos del trabajo radiofónico de ALER por su contenido y alcance. Estos son: Voces sobre la mesa, Voces de la Panamazonía y Contacto Sur en sus tres emisiones, que son transmitidas/producidas indistintamente en Venezuela, El Salvador, Honduras, República Dominicana, Bolivia, Chile, Colombia, Perú y, por supuesto, Ecuador.

La matriz permitió categorizar si las producciones presentaban sus narrativas desde: a) un contenido de denuncia, b) un acompañamiento a las comunidades, c) posibles soluciones a los problemas, y d) si el contenido refleja las realidades, esencias y reivindica el idioma originario. Estas categorías fueron establecidas por Hugo Ramírez, en su exposición desarrollada el lunes 22 de junio del año 2020, sobre la comunicación popular, en el Seminario de Narrativas Sonoras en tiempos de COVID, desarrollado por la carrera de Comunicación de la Universidad Politécnica Salesiana, sede Quito. El periodo de revisión de la programación seleccionada fue entre el 1 de octubre al 30 de diciembre del año 2020.

\section{Discusión y resultados}

Uno de los grandes debates fue lograr definir el trabajo de ALER desde lo popular o comunitario. Hugo Ramírez, director ejecutivo en funciones, especificó que 
sin duda alguna es popular, pues considera que "ALER reivindica el concepto de lo popular, porque quizás lo comunitario tiene algunas características que la hacen particular. Lo que marca su distinción es su proyecto político comunicativo, no importa qué apellido lleve, sea popular, comunitario eso es lo que marca su distinción" (comunicación personal, 23 de octubre de 2020).

Por su parte, María Cristina Mata (1993) también categoriza el trabajo de ALER como popular, pues más allá de una representación educadora y evangélica, las producciones radiofónicas permitieron consolidar líderes comunitarios, políticos y de incidencia, que emergieron de estos procesos radiales, lo que a su vez otorgó una visión de derechos a los sectores históricamente marginados; entonces, el trabajo sobrepasó la concepción de producción y se enmarcó en una perspectiva de acción que dinamizó la agenda política y pública de la sociedad ecuatoriana.

Una muestra de su postura ideológica y de su alineación con lo popular es que en el año 2016, en asamblea, proponen una modificación en el nombre original, pasó de llamarse Asociación Latinoamericana de Educación Radiofónica a Asociación Latinoamericana de Educación y Comunicación Popular. Para Leonel Herrera, presidente de la junta directiva de ALER, significó ampliar el espectro pues "no solo ha sido la práctica de comunicación sino también la escuela de comunicación a través de sus manuales, de las investigaciones y publicaciones" (comunicación personal, 17 de octubre de 2020). En este mismo sentido, Olmedo Carrasquilla, comunicador popular, simplifica el concepto en tres componentes: "la incidencia legal, la incidencia educativa y la incidencia social hacia el buen vivir de la población" (comunicación personal, 26 de octubre de 2020).

Roberto Sánchez Montoya (2018) considera que la investigación es parte del quehacer comunicacional; en el caso de ALER, las prácticas comunicativas trascienden de lo radial, pues existe un proceso investigativo que ha logrado conceptualizar lo popular, lo alternativo y comunitario desde la perspectiva comunicacional gracias a las múltiples publicaciones académicas, además de la práctica concreta de hacer radio particular, ya que se ha considerado vanguardista en procesos participativos colectivos. Uno de los principales aportes es el acompañamiento a las luchas populares, que han estado presentes en diversos países.

Desde la perspectiva de Jesús Martín-Barbero, lo popular es pasar de la teoría a la gente, es pensar a la comunicación desde el territorio; sin duda la asociación ha marcado una pauta clara y concreta con ayuda de organizaciones, la ciudadanía y los oyentes, y logra luchar por la recuperación de la democracia, incluso ante dictaduras. ALER no ha dejado esa lucha con la que empezó, busca siempre dar voz a quien no la tiene.

A más de abrir un micrófono, también implementó proyectos estratégicos de formación y capacitación para comunidades que están en el proceso de la construcción de un medio. Se les otorgó herramientas que trazan protocolos 
para la consolidación de los medios de comunicación; se orientó sobre los derechos humanos, la normativa de un Estado y las implicaciones que el legislativo tiene en torno a los derechos de comunicación.

Una de las grandes consignas que ALER ha trabajado es la revitalización de los idiomas originarios, para ello se consolidó la Red Kiechwa Satelital y la Red Maya, también se establecieron redes temáticas como América indígena en red, estas prácticas radiofónicas permiten tener una interlocución entre países y el intercambio de producción sonora. Martín-Barbero especificaría que para diversificar el contenido es importante hacer comunicación cultural, lo que implica la revitalización de las lenguas originarias y los conocimientos ancestrales.

El acompañamiento también se lo hace a las radios socias y asociadas sobre procesos internos y la construcción del proyecto radiofónico previo al concurso de frecuencias desarrollado por Arcotel, con la finalidad de establecer pluralidad de voces en el espectro radioeléctrico. Actualmente, ALER tiene un alcance tanto en costa, sierra, oriente y región insular del Ecuador.

Pese al esfuerzo de abrir nuevos espacios y dar cabida a la comunicación popular y comunitaria en Ecuador, uno de los problemas que aqueja a la red de ALER es el porcentaje de apenas el 34\%, que la Ley de Comunicación específica para las designaciones de radios comunitarias. En el art. 106 de la Ley Orgánica de Comunicación (2013, p. 48) se establece:

Las frecuencias del espectro radioeléctrico destinadas al funcionamiento de estaciones de radio y televisión de señal abierta se distribuirán equitativamente en tres partes, reservando el $33 \%$ de estas frecuencias para la operación de medios públicos, el 33\% para la operación de medios privados, y 34\% para la operación de medios comunitarios. [...] En todos estos casos, la distribución de frecuencias priorizará al sector comunitario hasta lograr la distribución equitativa que establece este artículo.

Esto implica que muchos medios queden fuera del concurso y de este porcentaje e incursionen en el mundo del internet. Incluso ALER consolida una comunicación alternativa satelital y se sustenta en una plataforma digital propia llamada Comrex, que son mini transmisores que funcionan con internet y satélite y permiten hacer transmisiones de manera real y mediata, como es el caso de la Radio Viajera, la Red Panamazónica, conectando territorios que parecen inaccesibles; además, disponen de cuentas propias en redes sociales.

Esta amplia visión de Vargas (2003) sobre la acción colectiva, permite entender el porqué ALER nunca ha dejado de trabajar en red, por eso la trayectoria del trabajo radial apunta a la consolidación de varias redes. Está por ejemplo la Red Amazónica de Corape, cuya participación comunicativa se da a través de la Red Panamazónica de ALER. Son dos producciones que apuntan a luchar por los pueblos amazónicos, sus territorios, la no depredación de 
la naturaleza, están en contra de los derrames de petróleo, invasión hacia los pueblos no contactados, entre otros aspectos.

En la Red Migración, que abarca producciones sobre el ser y sentirse migrante, en un aspecto más general, se han realizado campañas que se han ido recreando en cada país sobre temas específicos como el cuidado del ambiente, la migración, entre otros. Este tipo de prácticas tienen como finalidad entender que otra realidad es posible.

Por consiguiente, ALER, a lo largo de la historia, ha tratado temas que han sido importantes en cada una de sus épocas para crear conciencia, ya sea desde la denuncia o desde otros puntos de vista no ha dejado sola a la sociedad que ha necesitado de ella. Como asegura Roció Huamancondor: "Siempre ALER se ha parado a lado de las personas más vulnerables de nuestra sociedad. En algún momento las personas más vulnerables eran los indígenas, no digo que ahora no haya vulnerabilidad sino que hay nuevas vulnerabilidades como es la población migrante en este momento" (comunicación personal, 15 de octubre de 2020).

En torno al análisis del contenido de los tres programas insignias de ALER, se logró trabajar una frecuencia de revisión diaria, la programación seleccionada se analizó durante 13 semanas; en el caso de Voces sobre la mesa y Voces de la Panamazonía desarrollaron un programa semanal, lo que significa que fueron 13 programas estudiados, sin embargo, en Contacto Sur y sus tres transmisiones proporcionaron 39 emisiones para la revisión.

Gráfico 1. Contenido radiofónico

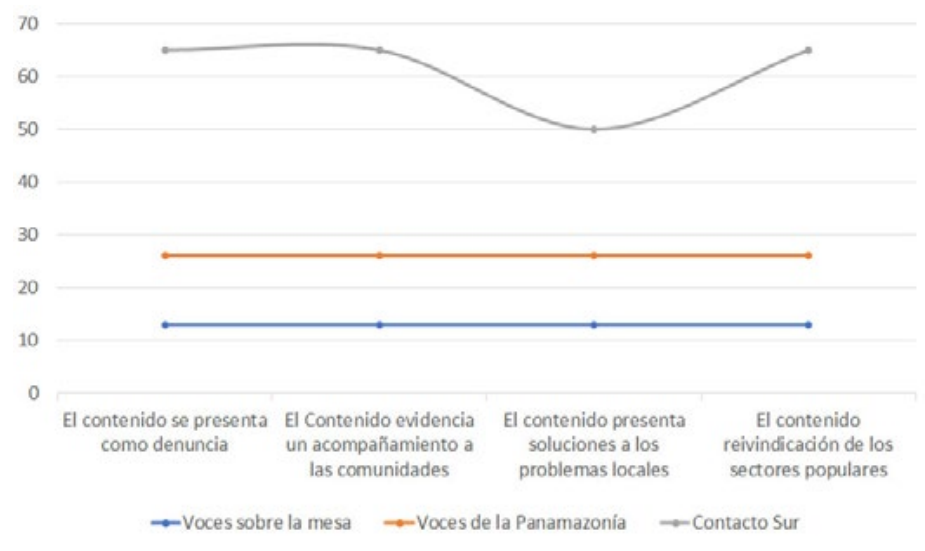

Fuente: Elaboración propia

En este sentido, el estudio muestra que Voces sobre la mesa y Voces de la Panamazonía cuentan con narrativas que evidencian un contenido de denuncia, lo que significa que están en constante cercanía y acompañamiento a las personas de los sectores marginados. La programación es un aporte al reconocimiento del 
trabajo comunitario y evidencia las necesidades de los sectores subalternizados, incluso otorgan una posible mediación a los problemas.

Por otra parte, Contacto Sur tiene un tratamiento noticioso informativo, lo que implica un ritmo de trabajo mediático, sin embargo, durante las 5 primeras semanas de análisis se evidenció que 15 programas revisados no orientaban el contenido a presentar posibles soluciones de los problemas reportados, los países que realizaron la producción del mes de octubre fueron Venezuela y El Salvador; los 24 programas restantes, cuyos países productores fueron Ecuador y Honduras, cumplieron con las 4 categorías de análisis, pues su trabajo mostró una cobertura pluralista.

El mayor reto de ALER es evidenciar, a través de sus prácticas comunicativas, otro tipo de comunicación, una que busque la integración de los pueblos, el acompañamiento y seguimiento a personas vulnerables. Pero también es cambio, transformación, fuerza, movilización, familia y vida. "ALER es reivindicar la comunicación" (Leonel Herrera, comunicación personal, 17 de octubre de 2020).

Quienes conforman la asociación, tanto interna como externamente, esperan que siga su presencia tanto en Latinoamérica y el Caribe, mediante un proceso formativo y desde el cambio social, que las prácticas comunicativas apunten al buen vivir, donde se establezca dinámicas distintas de convivencia, otras lógicas culturales, sociales y políticas. Como especificó Hugo Ramírez "no somos un medio, somos un actor y como tal si no estamos legitimados por estas organizaciones y por la ciudadanía, ese será el día que ALER va a perder su norte" (comunicación personal, 23 de octubre de 2020).

No obstante, como asociación también tienen problemas y el más visible es la sostenibilidad económica. ALER no es la coordinadora general en Quito son sus socias, asociadas y afiliadas en todo el continente, es un tejido comunitario social que se ve y oye cuando comparte con la gente que realiza comunicación desde los lugares más recónditos de América Latina y el Caribe. Por tanto, al reflexionar sobre la lucha de los pueblos, se aborda la comunicación popular, y al hacerlo, aparece necesariamente ALER.

\section{Conclusiones}

ALER se ha dedicado más de cuatro décadas al acompañamiento comunicacional a comunidades indígenas, campesinas, amazónicas y afrodescendientes alrededor de todo el territorio ecuatoriano. Este es un proceso que supera la visión asistencialista que presentó la comunicación alfabetizadora en sus inicios y que en la actualidad la posiciona como una red de redes temáticas.

$\mathrm{Su}$ incidencia en la sociedad civil ha sido reconocida por las funciones gubernamentales locales y nacionales, por lo que su poder de afiliación incrementa. Son ocho las emisoras en Ecuador y 117 a escala latinoamericana que comulgan con la misma dinámica, incentivar a los colectivos sociales a 
incursionar en procesos organizativos y el empoderamiento de sus derechos a través de la lucha social, además de construir propuestas radiales que vayan acorde a sus ideologías y concepciones. ALER ha enseñado a los oyentes a ser críticos de su propia realidad y no a ser consumidores pasivos.

Por lo tanto, las prácticas comunicativas de ALER responden a los procesos sociales, de derechos humanos y de educación. Sin embargo se sigue viendo a la educación como un elemento fundamental para el motor de una vida digna en la sociedad, lo que resta importancia a los procesos organizativos y de empoderamiento de derechos, no es posible entender la radio popular sólo como una figura alfabetizadora, si no se entiende primero que pasa por una toma de conciencia de los contextos opresores y que el poder intenta imponerse en la ciudadanía.

La comunicación popular ha significado un proceso revelador, pues permitió entender de qué manera se articuló la industria cultural en el mundo, y cómo este nuevo orden exigió una nueva forma de comunicar, mucho más pluralista, desde los sectores marginados, es ahí que el trabajo de ALER encamina la articulación de lo político con los movimientos sociales, lo que significó una lucha por una visión alternativa del trabajo de los medios y su relación con las comunidades.

Las organizaciones sociales son parte esencial de las comunidades, pues representan procesos dialógicos que producen significados, símbolos, y mensajes desde la perspectiva de la comunidad, tiene la capacidad de establecer espacios de diálogo y participación e interacción en el espacio público, su nivel de interlocución se da desde lo barrial y vecinal, lo que implica que poseen una diversidad de relación colectiva.

Además la programación, en su mayoría, logra alinearse con la esencia de la radio popular, aterriza el acompañamiento organizativo en la construcción de un discurso radiofónico intercultural, que evidencia los principales problemas de los sectores populares y posibilita una visión amplia de las responsabilidades gubernamentales y sociales para dar solución a los problemas evidentes, las narrativas sonoras apuntan a la democratización de la palabra y la información desde la diversidad de contenidos.

Si bien, las prácticas comunicativas de ALER, están vigentes y siguen alineadas a su propósito original, es a la audiencia con quien hay que trabajar, desde las mediaciones, Barbero especifica que el mayor reto de los medios populares y comunitarios es articular la industria cultural y el consumo, pues las lógicas aún se manejan desde los grandes grupos de poder que impiden lograr un cambio en la manera de pensar.

Por ello se ha logrado establecer otros espacios de resistencia, las nuevas tecnologías han impulsado una comunicación alternativa satelital, se trabaja desde plataformas de audio streaming, y tecnología Comrex que vienen a ser mini transmisores; y se logró mercantilizar el tiempo a través de las publicaciones por redes sociales y sitios webs. No obstante no ha dejado de lado la radio, pese 
a no ser catalogada como una nueva tecnología también se ha ido innovando con el tiempo, pues ha logrado convertirse en un espacio multimediático.

Aún cuando el trabajo de ALER sigue siendo en red, no se ha logrado competir con los sistemas mediáticos de otros espacios, el desafío actual es lograr ganar viralidad a través de los contenidos emitidos, y presencia social; es importante entender a las nuevas sensibilidades colectivas y las preferencias de estas, y así no poner en riesgo constante la sostenibilidad de los medios populares y comunitarios.

Es evidente que en Ecuador no se le da la importancia que se debería a la comunicación popular y mucho menos a la radio popular. Sin embargo, se puede cuestionar: ¿por qué si es un país rico con diferentes etnias en el Ecuador, las radios populares y comunitarias y por ende la comunicación popular y comunitaria son parte de una minoría y no tiene un espacio adecuado para crecer en nuestro país?

$\mathrm{Y}$, si somos un país democrático ¿por qué las radios populares y comunitarias no tienen la misma acogida por los oyentes y no se les da eco a sus voces? ¿Cómo generar procesos donde lo económico no sea la principal preocupación? y ¿Cuál es el manejo de información e investigación que se realiza de parte de los periodistas y corresponsales no solo en nuestro país sino también en América Latina y el Caribe?

Esta investigación condujo a replantearse la noción tanto de la comunicación popular y comunitaria, vista como una propuesta alternativa al contenido mediático sesgado de los grandes monopolios, lo popular no está en vigencia porque a los intereses de los grupos de poder no les conviene. Sin embargo, la comunicación popular y comunitaria empieza a tener el reconocimiento de la sociedad, lo que implica que existe competencia simbólica en el campo de la comunicación.

\section{Referencias bibliográficas}

Alaiza, M. D. (2002). Comunicación popular: del paradigma de la dominación al de las mediaciones sociales y culturales. Vol. 21. Quito: Abya-Yala.

ALER. (2020). Acerca de ALER. Recuperado de https://aler.org

ALER. (1991). ALER 500 años. Chasqui. Revista Latinoamericana de Comunicación, 40: 85. Amati, M., Isella, J., \& Lois, I. (2014). Comunicación popular, educativa y comunicativa. Curso Anual de Comunicación Popular. Buenos Aires: Universidad de Buenos Aires.

Asamblea Nacional del Ecuador. Ley Orgánica de Comunicación. Registro oficial 22, 25 de junio de 2013 .

Beltrán, G. (2018). Crisis de las radios comunitarias en el Ecuador. ESTRATEGAS, Investigación en Comunicación, Vol. 5. ISSN: 2550-6870. Recuperado de https://marketing.udla. edu.ec/ojs/index.php/estrategas/article/view/158/o

Busso, N. (2019). Radios populares, comunitarias, alternativas, ciudadanas. Agencia Prensa Rural. Recuperado de https://prensarural.org/spip/spip.php?article23848

Gutiérrez, H. (1997). La radio popular: Entre lo local y lo global. Chasqui. Revista Latino- 
americana de Comunicación, (59), 29-32.

Kaplún, G. (2007). La comunicación comunitaria. Anuario de medios, 312.

Martínez Rodríguez, J. (2011). Métodos de investigación cualitativa. Silogismo, Vol. 4, N. ${ }^{\circ} 8$. Educadores solidarios con el progreso de los colombianos. Recuperado de http://saber. cide.edu.co/ojs3.2/index.php/silogismo/article/view/111

Mata, M. C. (1993). ¿Radio popular o comunitaria? Chasqui. Revista Latinoamericana de Comunicación, (47), 57-59.

Motta, L. G. (1983). Comunicación popular y los modelos transnacionales (Entrevista a Jesús Martín-Barbero). Chasqui: Revista Latinoamericana de Comunicación, (8), 4-11.

Pico Florez, I. J. (2009). La construcción simbólica de los derechos de la comunicación en la propuesta informativa de la Asociación Latinoamericana de Educación Radiofónica ALER (Tesis de maestría). Quito: Flacso-E.

Quecedo Lecanda, R., \& Castaño Garrido, C. M. (2002). Introducción a la metodología de investigación cualitativa. Revista de psicodidáctica, 7 .

Sánchez, P. (1989). El sistema ALER. Chasqui Revista Latinoamericana de Comunicación, 58-59.

Sánchez, R. M. S. (2018). Medios de comunicación privados y poder político en Ecuador 20072016. Quito: Abya-Yala.

Unesco. (2020). Día Mundial de la Radio. Recuperado de https://es.unesco.org/commemorations/worldradioday

Valencia, J. C., \& Magallanes, C. (2016). Prácticas comunicativas y cambio social: potentia, acción y reacción. Univ. humanist. [online], N. ${ }^{\circ}$ 81, pp. 15-31. ISSN 0120-4807. https:// doi.org/10.11144/Javeriana.uh81.pces

Vargas, J. G. (2003). Teoría de la acción colectiva, sociedad civil y los nuevos movimientos sociales en las nuevas formas de gobernabilidad en Latinoamérica. Espacio abierto, 12(4).

Van Dijk, Teun A. (1980). La noticia como discurso. Comprensión, estructura y producción de la información. Madrid: Paidós.

Verón, E. (1993). Fragmentos de un tejido. Barcelona: Gedisa. 